\title{
Thalamic interaction between the input and the output systems of the basal ganglia
}

\author{
Elisa Mengual a, Silvano de las Heras ${ }^{b}$, Elena Erro a, José Luis Lanciego a, \\ José Manuel Giménez-Amaya ${ }^{a, *}$ \\ a Departamento de Anatomía, Facultad de Medicina, Universidad de Navarra, C/ Irunlarrea, 1, 31008 Pamplona, Spain \\ ${ }^{\mathrm{b}}$ Departamento de Morfología, Facultad de Medicina, Universidad Autónoma de Madrid, 28029 Madrid, Spain
}

Received 6 April 1998; received in revised form 22 October 1998; accepted 14 February 1999

\begin{abstract}
The striatal return through the thalamus is largely neglected in current studies dealing with basal ganglia function, and its role within this circuitry remains obscure. In this contribution the thalamus is regarded as an important place of interaction between the input and the output organization of the basal ganglia. In support of this idea, a brief overview is provided of some of the most recent findings concerning the thalamus in relation to the basal ganglia circuitry. In particular, we have focused on the thalamostriatal projections themselves, on the output of the basal ganglia to the thalamus and also on the overlapping territories between the thalamic projection of the output nuclei and the thalamostriatal neurons. These data support the existence of several thalamic feedback circuits within the basal ganglia neural system. Finally, some considerations are provided upon the functional significance of these thalamic feedback circuits in the overall organization of the basal ganglia. (C) 1999 Elsevier Science B.V. All rights reserved.
\end{abstract}

Keywords: Thalamus; Basal ganglia; Striatum; Globus pallidus; Substantia nigra; Rat; Cat; Monkey

\section{Introduction}

The basal ganglia form a group of subcortical nuclei functionally linked with the organization of complex motor behaviors and also with cognitive and motivational aspects of behavior (Nauta and Feirtag, 1986; Graybiel, 1995; Schultz, 1997). They are involved in a great looping circuit in which neocortical and other afferent systems can be brought back onto the motor cortex after a sequential connectional array between the input and the output nuclei of the basal ganglia. The cortical input reaches the basal ganglia through its main input structure, the striatum, and after neural processing at the striatal level, it is conveyed towards the main output nuclei, namely the internal globus

\footnotetext{
* Corresponding author. Tel.: + 34-948-425685; fax: + 34-948425649.

E-mail address: jmga@unav.es (J. Giménez-Amaya)
}

pallidus (entopeduncular nucleus in non-primates) and the substantia nigra pars reticulata (Graybiel and Ragsdale, 1979; Alexander et al., 1986; Parent, 1986; Alheid et al., 1990; Giménez-Amaya, 1991a,b; Hoover and Strick, 1993; de las Heras et al., 1994; Heimer et al., 1995; Gerfen and Wilson, 1996). The outflow of the basal ganglia is then relayed to the thalamus, from where it is driven back to the cerebral cortex closing the neural circuit. In addition, the internal segment of globus pallidus and the pars reticulata of the substantia nigra also project to premotor regions of the brainstem. Finally, diverse internal regulatory loops are also present among other components of the basal ganglia, such as the nigrostriatal dopaminergic pathway from the pars compacta of the substantia nigra, and the regulatory loop from the external segment of the globus pallidus to the subthalamic nucleus (Parent, 1986; Alheid et al., 1990; Heimer et al. 1995; Gerfen and Wilson, 1996). 
In addition to the cerebral cortex, the thalamus constitutes another important source of excitatory inputs to the striatum (see references in Parent, 1986; Alheid et al., 1990). This structure, at the crossroads of brainstem, basal ganglia and telencephalic circuits, is actively implicated in shaping afferent signals through inhibitory processes and it participates in highly complex integrative functions (Steriade et al., 1997). The thalamostriatal projections were firstly demonstrated in humans by Vogt and Vogt in 1941 (Vogt and Vogt, 1941; Parent, 1986) and since then they have been described in the majority of species. These striatal afferent projections from the thalamus appear to be almost exclusively ipsilateral and they innervate the whole striatum (caudate nucleus and putamen), including its most ventral and medial part, the nucleus accumbens (Parent, 1986; Alheid et al., 1990).

Although the thalamostriatal connections have been subject of numerous studies in different species, and despite the fact that these projections are included or mentioned in some models of basal ganglia organization (Alexander and Crutcher, 1990; Chesselet and Delfs, 1996), current studies dealing with the basal ganglia function and/or dysfunction actually neglect this striatal return. This has been pointed out by several authors (Féger, 1997; Chesselet and Delfs, 1997; Smith et al., 1998). In contrast, physiological and clinical studies point to the thalamus as a key structure within the neural circuitry of the basal ganglia (Marsden and Obeso, 1994; Schneider and Rothblat, 1996; Wichmann and DeLong, 1996). However, its role within the basal ganglia function remains obscure. The goal of this article is to make a brief overview of some of the more recent findings concerning the thalamus in relation to the basal ganglia circuitry. In particular, we will focus on the thalamostriatal projections themselves, on the output of the basal ganglia to the thalamus and also on the overlapping territories between the thalamic projection of the output nuclei and the thalamostriatal neurons. When all these data are taken into account, the thalamus merges as an important place of interaction between input and output systems of the basal ganglia, and some light is thrown on the role that the thalamus could be playing in this neural circuitry.

\section{The thalamostriatal projections}

Early retrograde degeneration methods demonstrated that the main origin of the thalamostriatal projections were the rostral (central medial, paracentral and central lateral nuclei) and caudal (centromedian and parafascicular nuclei) intralaminar nuclei (Drooglever-Fortuyn and Stefens, 1951; Powell and Cowan, 1954; Cowan and Powell, 1955; Powell and Cowan, 1956). These projections to the striatum were confirmed by means of more modern tracing techniques, and additional thalamic projections have been also demonstrated. Thus, projections from the midline thalamic nuclei (paraventricular, paratenial, rhomboid and reuniens nuclei), the mediodorsal nucleus, the rostral nuclei of the ventral group and occasional projections from the lateral and posterior thalamic groups have been reported (Jones and Leavitt, 1974; Nauta et al., 1974; Royce, 1978; Sato et al., 1979; van der Kooy, 1979; Veening et al., 1980; Beckstead, 1984a,b; Macchi et al., 1984; Jayaraman, 1985; Philipson and Griffiths, 1985; Smith and Parent, 1986; Berendse and Groenewegen, 1990; Nakano et al., 1990; Giménez-Amaya et al., 1995; de las Heras et al., 1997, 1998a,b, 1999).

From retrograde tracing studies after injections in the striatum, a clear segregation was soon established between the thalamic nuclei projecting to the dorsal striatum and the ones projecting to the ventral striatum, so that when we move down along the dorsoventral coordinate within the striatum, there is a gradual shift from medial to lateral in the localization of the thalamostriatal neurons. An example of this arrangement appears in Fig. 1, which shows the distribution of retrogradely labeled cells in the rat thalamus after two injections of the retrograde tracer Fluorogold (FG) in dorsal and ventral regions of the rat caudate putamen complex (Fig. 1, for methodological considerations see Lanciego et al., 1998). Thus, medially located nuclei, namely, the midline thalamic nuclei, the mediodorsal nucleus and the parafascicular nucleus (the medial portion of the parafascicular nucleus in the rat) send projections to the ventral striatum, whereas more laterally located nuclei, such as the rostral intralaminar nuclei, the centromedian nucleus (the lateral portion of Pf in the rat), the ventral nuclei and the lateral and posterior groups, project to the dorsal striatum and dorsal putamen (Beckstead, 1984a; Nakano et al., 1990; Berendse and Groenewegen, 1990; Giménez-Amaya et al., 1995; Erro et al., 1998). Accordingly, some medially located neurons within the ventral, anterior, medial, and lateral thalamic groups also contribute to the thalamostriatal projections to the ventral striatum in the primate (Nakano et al., 1990; Giménez-Amaya et al., 1995).

In addition to this nuclear segregation that characterizes the thalamostriatal projections in relation to their target region within the striatum, and focusing on the dorsal striatum, there are some other features in the organization of the thalamostriatal projections that are commonly shared only by the projections arising from specific thalamic nuclei. Thus, thalamic neurons in the ventral nuclei (ventral anterior, ventral lateral and ventral medial thalamic nuclei) are retrogradely labeled almost exclusively after rostral injections in the rostral caudate nucleus, that is, they almost exclusively project to rostral striatal areas (Tanaka et al., 1986; Erro et al., 1998; de las Heras et al., 1998b, 1999). Within these 
C-8
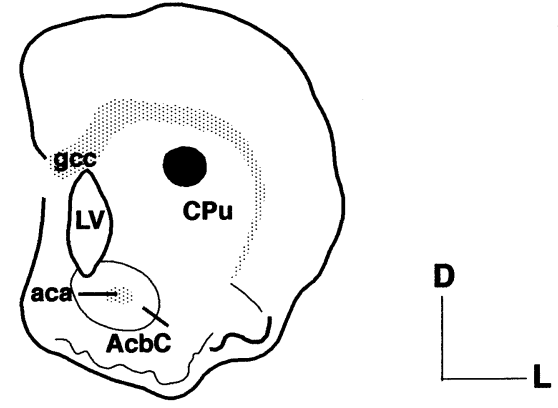
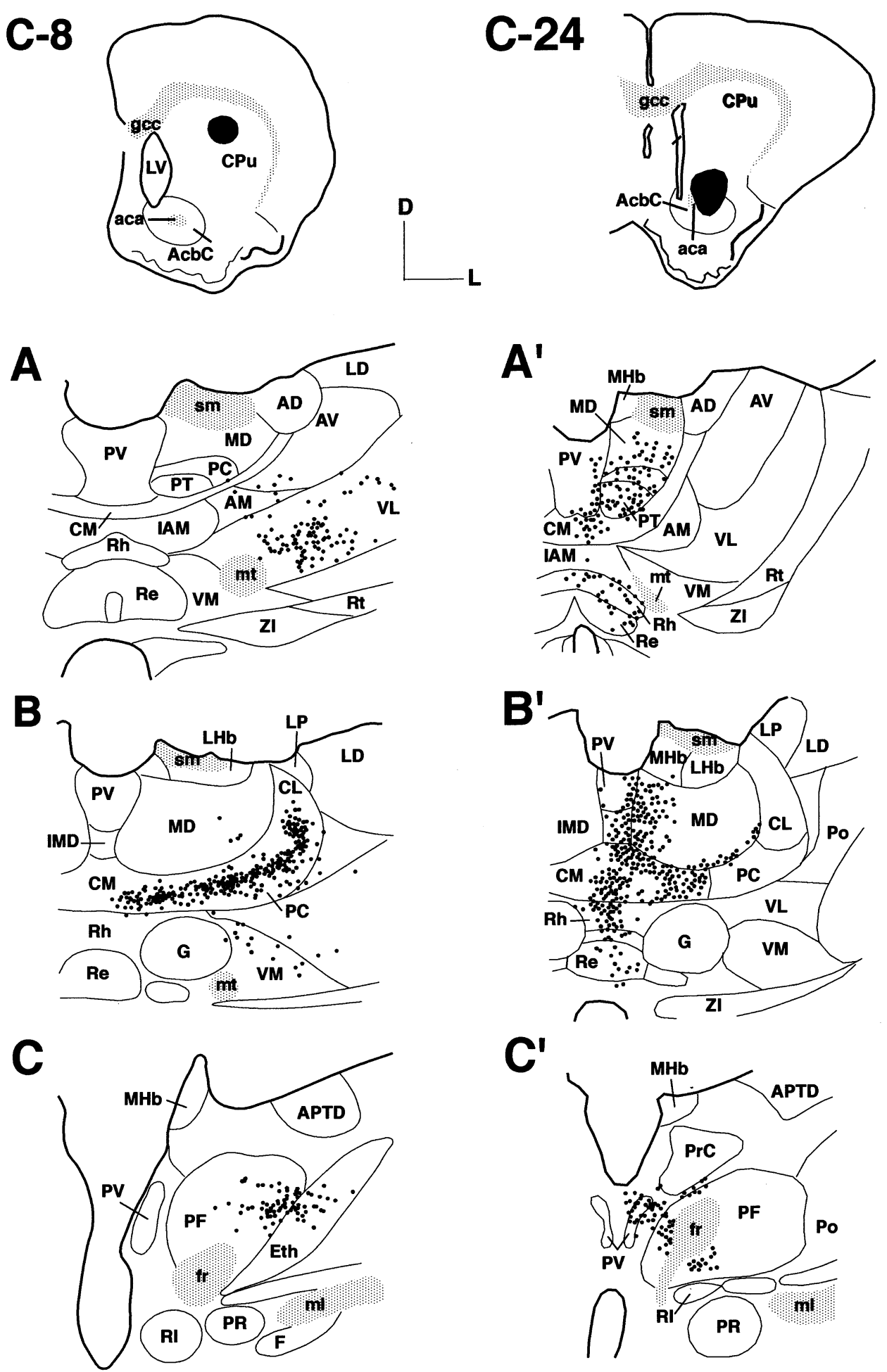

Fig. 1. Schematic drawings illustrating two examples of the organization of the thalamostriatal neurons in the rat projecting to different regions of the caudate putamen complex, after single injections of the retrograde tracer Fluorogold (FG) in the caudate putamen complex. Left (top) injection site in the dorsal portion of the caudate putamen complex and (A-C), retrogradely labeled neurons from case C-8. Right (top) injection site in the ventral portion of the caudate putamen complex and $\left(\mathrm{A}^{\prime}-\mathrm{C}^{\prime}\right)$, retrogradely labeled neurons from case $\mathrm{C}-24$. Note the clear mediolateral topography displayed by the thalamic cells projecting to dorsal vs. ventral regions of the caudate putamen complex. Each dot represents one retrogradely labeled neuron. Stippled areas correspond to fiber tracts. Abbreviations: aca, anterior commisure, anterior part; AcbC, accumbens nucleus, core; AD, anterodorsal nucleus; AM, anteromedial nucleus; APTD, anterior pretectal nucleus, dorsal part; AV, anteroventral nucleus; CL, centrolateral nucleus; $\mathrm{CM}$, central medial nucleus; $\mathrm{CPu}$, caudate putamen; Eth, ethmoid nucleus; F, nucleus of the fields of Forel; fr, fasciculus retroflexus; G, gelatinosus nucleus; gcc, genu of the corpus callosum; IAM, interanteromedial nucleus; IMD, intermediodorsal nucleus; LD, laterodorsal nucleus; LHb, lateral habenular nucleus; LP, lateral posterior nucleus; LV, lateral ventricle; MD, mediodorsal nucleus; MHb, medial habenular nucleus; ml, medial lemniscus; mt, mammillothalamic tract; PC, paracentral nucleus; PF, parafascicular nucleus; Po, posterior nuclear group; PR, prerubral field; PrC, precommisural nucleus; PT, paratenial nucleus; PV, paraventricular nucleus; Re, reuniens nucleus; Rh, rhomboid nucleus; RI, rostral interstitial nucleus of the medial longitudinal fasciculus; Rt, reticular nucleus; sm, stria medullaris of the thalamus; VL, ventrolateral nucleus; VM, ventromedial nucleus; ZI, zona incerta. 


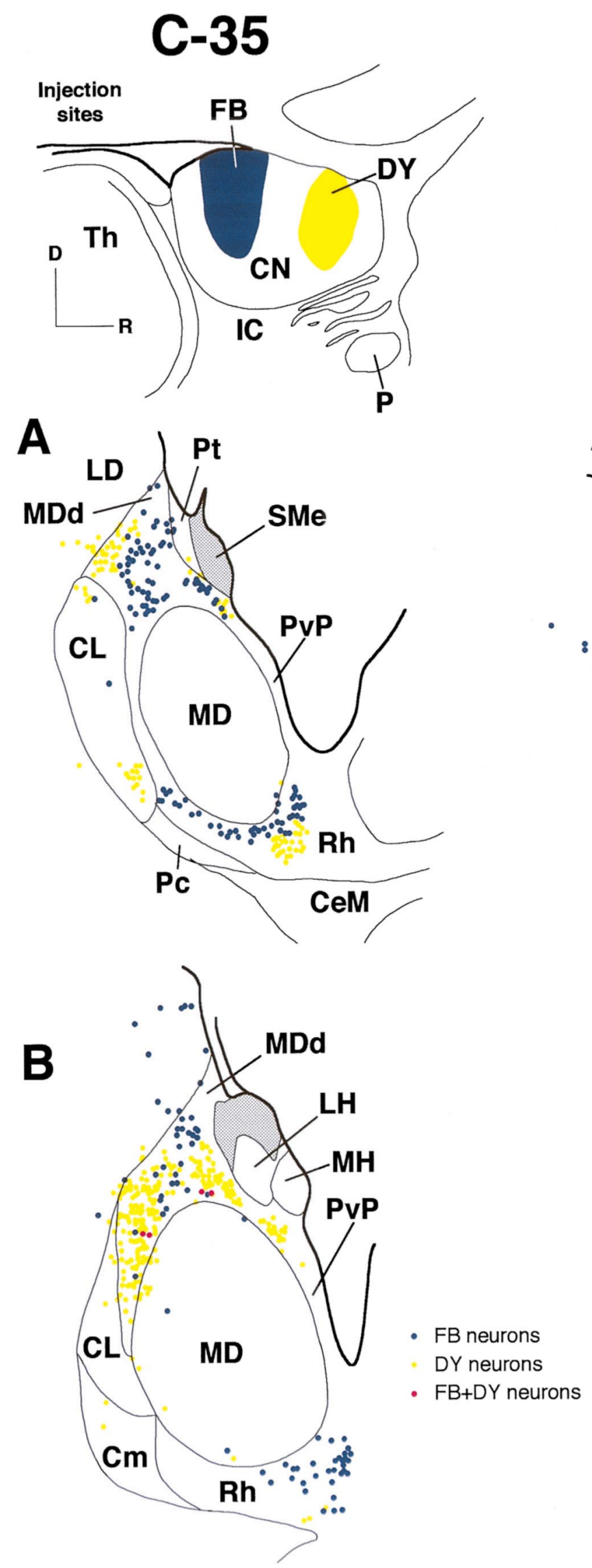

C-36

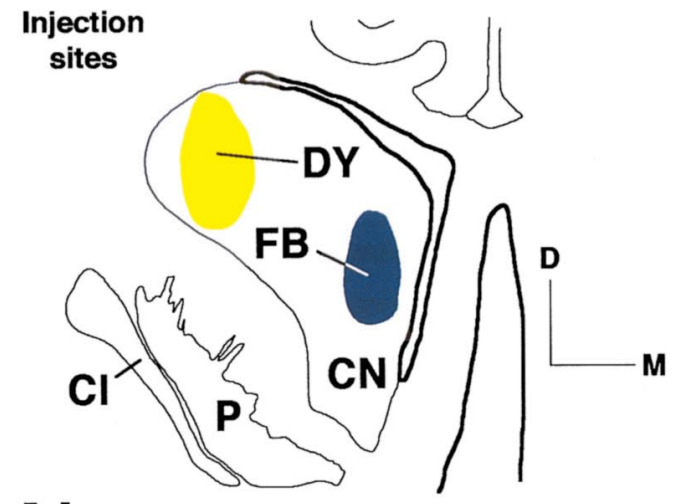

$A^{\prime}$

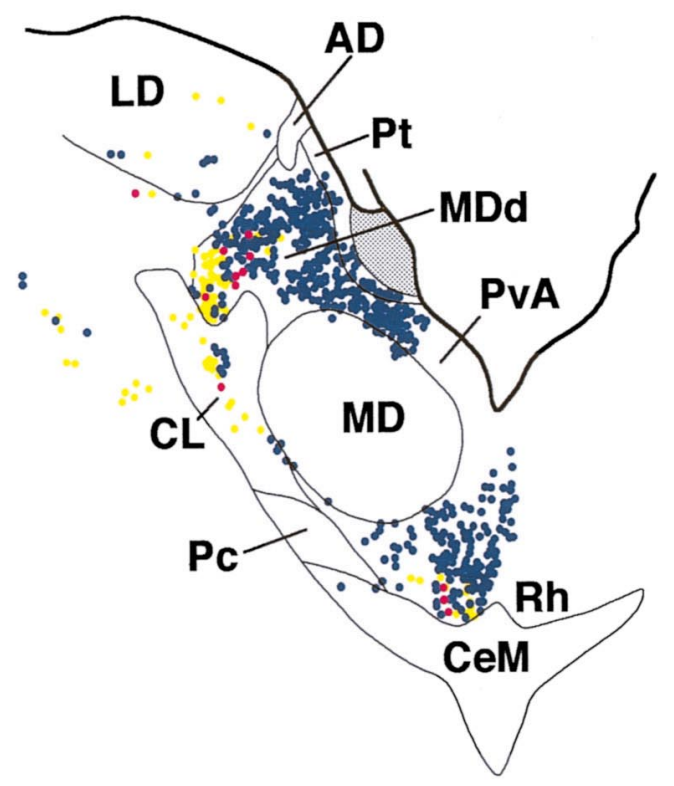

Fig. 2.

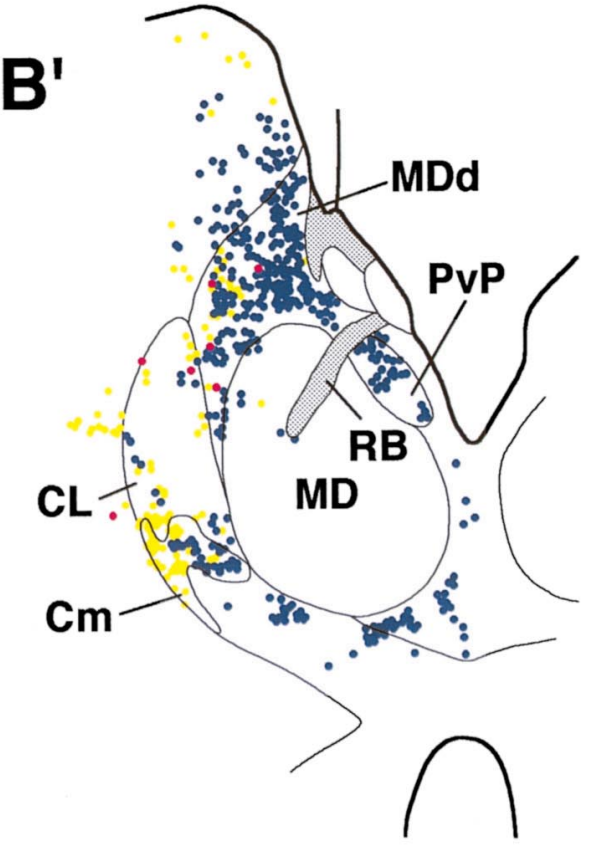


nuclei, the retrogradely labeled neurons after single tracer injections in the striatum appear widely distributed and organized in dorsoventral bands (Tanaka et al., 1986; de las Heras et al., 1997, 1998a,b, 1999), with a consistent mediolateral topography to corresponding areas of the striatum in the different species (Tanaka et al., 1986; Nakano et al., 1990; de las Heras et al., 1997, 1998a,b, 1999; Erro et al., 1998). Remarkably, no double-labeled neurons could be found in any of these nuclei after two fluorescent tracer deposits in different rostrocaudal, dorsoventral or mediolateral regions of the cat caudate nucleus or after putamen vs. caudate nucleus deposits in the squirrel monkey (Fig. 2, for methodological considerations see de las Heras et al., 1999; see also Parent et al., 1983; de las Heras et al., 1997, 1998a, 1999). This may indicate the high specificity of the topographical thalamostriatal projections arising from the subdivisions of the ventral nuclei, which is emphasized by the high degree of segregation displayed by the motor-related subcortical afferents to these subdivisions (see Section 3).

In contrast, some other features characterize the thalamostriatal projections arising from the rostral intralaminar nuclei. After deposits of retrograde tracers in different regions of the striatum, retrogradely labeled cells are always present within these nuclei (Figs. 1 and 2 ). In the cat, however, a higher number of cells within the lateral wing of the rhomboid nucleus and the dorsal mediodorsal nucleus were projecting to the rostral regions of the caudate nucleus, whereas the caudal part of the rhomboid nucleus seemed to project mainly to caudal striatal areas (Fig. 2A-B). A certain mediolateral topography could also be observed, so that medial injections gave rise to retrograde labeling closer to the ventricle than lateral injections, in a somewhat center-periphery fashion (Fig. 2A'-B' and de las Heras et al., 1998b; Erro et al., 1998). Contrarily to the widespread distribution pattern observed in the ventral nuclei, the thalamostriatal cells within the rostral intralaminar nuclei were arranged in dense clusters (Parent et al., 1983; de las Heras et al., 1998b, 1999) and when two retrograde tracers were used, the clusters containing one tracer were intermingled with the ones containing the other. This arrangement suggests a possible modular organization of this projection. These neurons do collateralize within the striatum, as revealed by the presence of double-labeled neurons, although their number is very low (Fig. 2 and Parent et al., 1983; de las Heras et al., 1999). Such collateralization occurs both in the mediolateral and rostrocaudal coordinates but not in the dorsoventral coordinate in the cat striatum (de las Heras et al., 1999). Remarkably enough, the double-labeled neurons tend to be localized at the transitional areas between the two single labeled populations (Fig. 2A-B, $\left.2 \mathrm{~A}^{\prime}-\mathrm{B}^{\prime}\right)$. These findings are in keeping with the data obtained from axonal tracing after very small injections of biocytin in the central lateral nucleus or in associative thalamic nuclei, such as the mediodorsal or the lateral dorsal nuclei, in the rat. The axons of these cells, which were typical bushy relay cells, were found to arborize sparsely in the striatum, forming well-defined rostrocaudally oriented bands of varicose, loosely organized collaterals, which seemed to contact en passant a large number of neurons (Deschênes et al., 1995). This loosely organized collateralization may account for the poor retrograde labeling displayed by thalamostriatal neurons within the rostral intralaminar nuclei after localized retrograde tracer injections (de las Heras et al., 1999).

The main source of thalamostriatal inputs to the striatum are the caudal intralaminar nuclei. Thus, retrogradely labeled neurons were consistently found in the parafascicular nucleus in the rat (Fig. 1), in the centromedian-parafascicular complex in the cat (Beckstead, 1984a; Jayaraman, 1985; de las Heras et al., 1998b, 1999), and either in the centromedian or the parafascicular nuclei in the squirrel monkey or primate, after deposits of retrograde tracers in any striatal region (Parent et al., 1983; Nakano et al., 1990; Sadikot et al., 1992a). Again, this is consistent with anterograde tracing studies and axonal labeling studies which have shown the wide rostrocaudal extension of these projections, so that depending upon the site of injection into the parafascicular and centromedian or ethmoid nuclei, labeled fibers could be found in all regions of the dorsal striatum (Sadikot et al., 1992a; Deschênes et al., 1996).

A clear topography has been detected in the thalamostriatal projection from the caudal intralaminar nuclei in the primate (Parent et al., 1983; Nakano et al., 1990; Fénelon et al., 1991; Sadikot et al., 1992a), and a certain mediolateral topography has been also described in the cat (Beckstead, 1984a; de las Heras et al., 1999) and rat (Erro et al., 1998). Sparse double-labeled cells were

Fig. 2. Schematic drawings illustrating the organization of the distinct thalamostriatal neuronal populations projecting to two different regions of the caudate nucleus, after concomitant injections of two retrograde fluorescent tracers, Fast Blue (FB) and Diamidino Yellow (DY), in the cat. Left (top) localization in a sagittal drawing, of the FB and DY deposits in different rostrocaudal sectors of the caudate nucleus, and (A-B), retrogradely labeled neurons from case C-35. Right (top) localization in a coronal drawing of the FB and DY injections in different mediolateral sectors of the cat caudate nucleus, and $\left(\mathrm{A}^{\prime}-\mathrm{B}^{\prime}\right)$, retrogradely labeled neurons from case $\mathrm{C}-36$. Each dot represents one retrogradely labeled neuron. FB neurons are depicted in blue, DY neurons in yellow, and double-labeled neurons in red. Abbreviations: AD, anterodorsal nucleus; CeM, central medial nucleus; Cl, claustrum, CL, central lateral nucleus; Cm, centromedian nucleus; CN, caudate nucleus; D, dorsal; DY, Diamidino Yellow; FB, Fast Blue; IC, internal capsule; LD, laterodorsal nucleus; LH, lateral habenular nucleus; MD, mediodorsal nucleus; MDd, dorsal mediodorsal nucleus; MH, medial habenular nucleus; P, putamen; Pc, paracentral nucleus; Pt, paratenial nucleus; PvA, anterior paraventricular nucleus; PvP, posterior paraventricular nucleus; R, rostral; RB, retroflex bundle; Rh, rhomboid nucleus; SMe, stria medullaris; Th, thalamus. 
detected in the monkey (Parent et al., 1983), whereas in the cat the number of double-labeled cells was slightly higher than in the rest of thalamic nuclei (de las Heras et al., 1999). Remarkably, the thalamostriatal cells within the rat parafascicular and ethmoid nuclei were morphologically different from the bushy cells located in the rostral intralaminar and associative thalamic nuclei, and so were their terminations in the target areas. Thus, these large relay cells resembling those of the reticular thalamic nucleus with few and poorly branched dendrites, gave rise to thalamic fibers that branched heavily in the striatum, forming well-spaced and dense clusters of terminals (Deschênes et al., 1996). Interestingly, these axons continue towards the cortex where they branch very sparsely, whereas the thalamostriatal fibers arising from the bushy cells, arborize more heavily in the cerebral cortex (Deschênes et al., 1995).

The diversity of termination patterns of thalamostriatal projections is further widened when it is taken into account that they are also organized following the compartmental striatal chemoarchitecture (Berendse et al., 1988; Ragsdale and Graybiel, 1991; Sadikot et al., 1992b; Deschênes et al., 1996). A detailed study of the termination of the caudal intralaminar nuclei in the squirrel monkey reveals that both the centromedian and the parafascicular thalamic fibers terminate exclusively on the matrix compartment, but in addition, the heterogeneity is further increased in regard to their postsynaptic elements, given that the centromedian nucleus terminates to a higher extent on dendritic spines than the parafascicular nucleus (Sadikot et al., 1992b).

In summary, the wide variety of organization patterns within the thalamostriatal projections regarding their thalamic arrangement, their collateralization and their termination patterns, reveals that this projection, as a whole, may be more complex than previously thought, and also allows to hypothesize whether different subsets or even different systems of thalamostriatal projections, whose influence were completely different from each other might underlie the thalamostriatal organization.

\section{The output organization of the basal ganglia to the thalamus}

The internal segment of the globus pallidus (entopeduncular nucleus in non-primates) and the pars reticulata of the substantia nigra are the main output nuclei of the basal ganglia, which convey the information processed within the basal ganglia towards the thalamus and also towards several structures within the midbrain tegmentum (see, for review, Parent and Hazrati, 1995a). In addition, the external segment of the globus pallidus (globus pallidus in non-primates) also projects to the thalamus, though less prominently (see, for review, Parent and Hazrati, 1995b).

The main thalamic recipients of the basal ganglia outflow are, the so-called motor thalamus, which comprises mainly the ventral anterior and ventral lateral nuclei and the ventral medial nucleus to some extent, and the rostral and caudal intralaminar nuclei (Ilinsky and Kultas-Ilinsky, 1987). There are additional thalamic nuclei that receive pallidal/nigral connections, such as the mediodorsal and reticular thalamic nuclei, and the lateral habenula which specifically receives afferent connections from the internal segment of the globus pallidus (Nauta, 1979; De Vito and Anderson, 1982; Ilinsky et al., 1985; Sakai et al., 1996).

The terminal fields of both pallidal and nigral afferents to the thalamus have been extensively studied in several species (see references in Sidibé et al., 1997; Sakai et al., 1998). In the primate thalamus, both the motor thalamus and the caudal intralaminar nuclei are well-developed, with architectonically distinct nuclei and subnuclei (Asanuma et al., 1983; Ilinsky and Kultas-Ilinsky, 1987; Stepniewska et al., 1994). In this species, pallidal and nigral afferents are largely segregated, so that the nigral afferents terminate in the medial portion of the ventral anterior nucleus, in the mediodorsal nucleus and in the ventral portions of $\mathrm{Cm}-\mathrm{Pf}$, whereas pallidal projections occupy the lateral portions of VA and the oral (anterior) portion of the ventral lateral nucleus, the ventral medial nucleus, and the centromedian and parafascicular nuclei (Ilinsky et al., 1985; Ilinsky and Kultas-Ilinsky, 1987; Percheron et al., 1993, 1996; Sakai et al., 1996; Sidibé et al., 1997). Regarding the remaining species, although there seems to be a progressive increase in the segregation of circuits from rodents to carnivores to primates in the organization of the motor thalamus (Kultas-Ilinsky and Ilinsky, 1986; Sakai and Patton, 1993), and probably in the caudal intralaminar nuclei as well, such segregation is also basically observed in the motor thalamus and caudal intralaminar nuclei in the carnivores (Hendry et al., 1979; Nauta, 1979; Sakai and Smith, 1992; Sakai and Patton, 1993). In rodents, a gross segregation is visible, so that the nigral afferents occupy a more medial position than the pallidal afferents in the ventral anterior-ventral lateral nucleus (compare Fig. 3A with Fig. 3 from Sakai et al., 1998), and also in the rostral intralaminar and mediodorsal nuclei, where even a complementary pattern is hinted (see Fig. 3A-A', B-B'; for methodological considerations see Lanciego et al., 1998). The segregation is less clear in the parafascicular nucleus, but the preferential terminal field of nigral afferents is more medially located than the pallidal one (Fig. 3C-C'). In contrast, the ventral medial nucleus seems to be a highly convergent nucleus both in rodents and carnivores (see Fig. 3A-A', B-B', and Hendry et al., 1979; Sakai and Patton, 1993). 

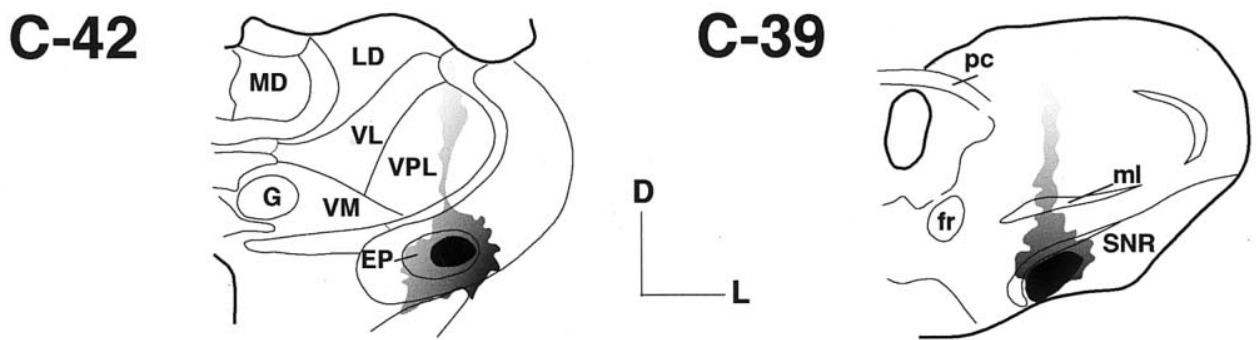

A

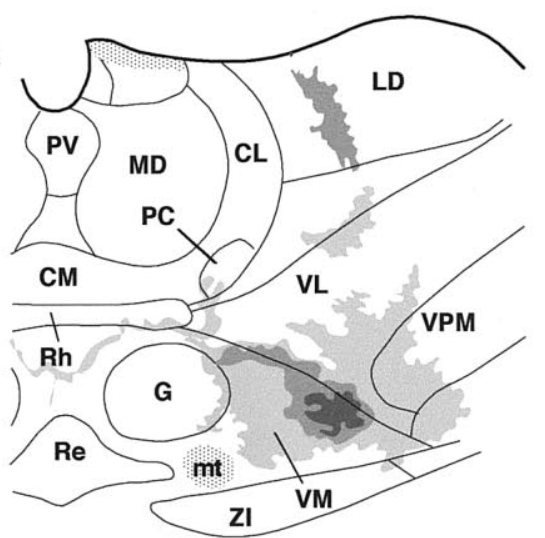

B
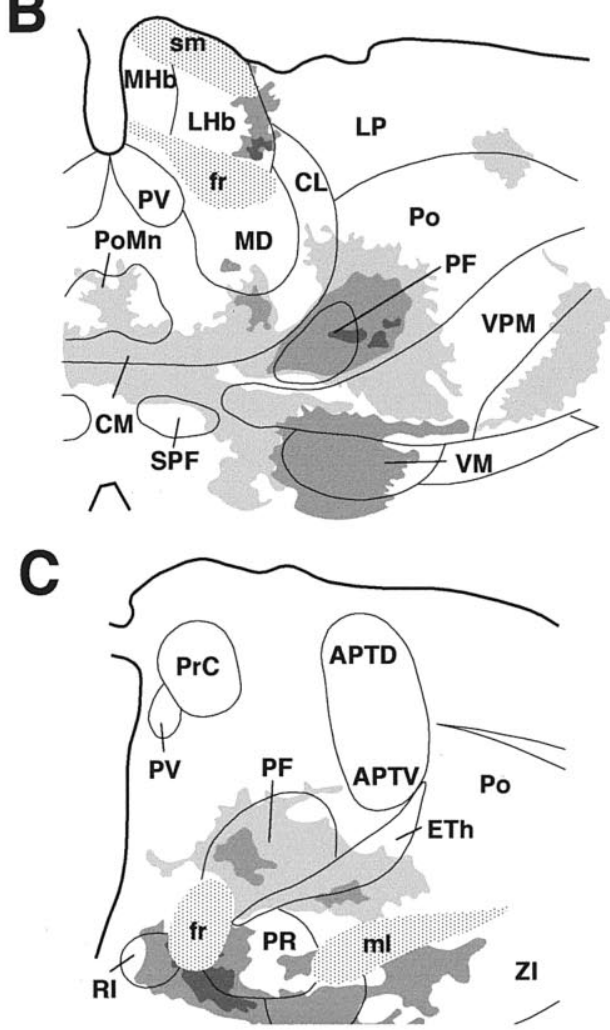

$A^{\prime}$

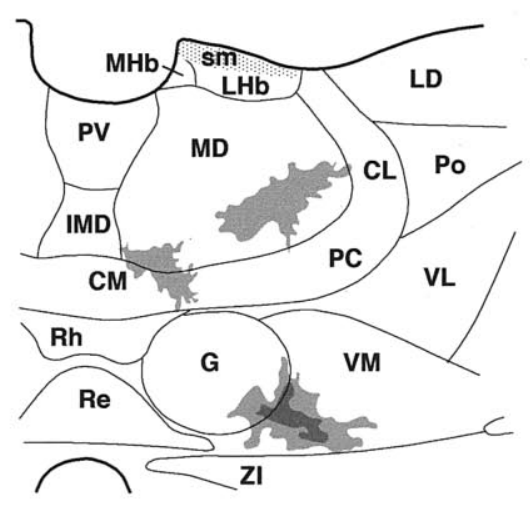

B'
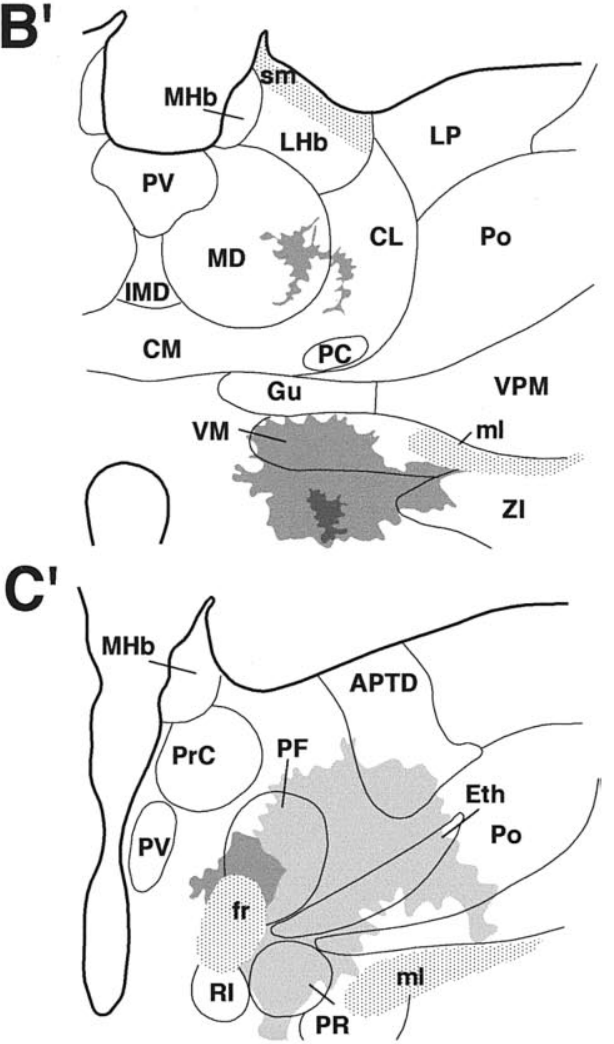

Fig. 3. Schematic drawings illustrating the terminal fields of pallidothalamic and nigrothalamic fibers in the rat, after injections of the anterograde tracer byotinilated dextran amines (BDA). Anterogradely labeled terminal fields are represented by shaded areas. Left (top) injection site in the entopeduncular nucleus from case C-42, and (A-C), anterograde labeling in a rostrocaudal sequence. Right (top) injection site in the substantia nigra from case $\mathrm{C}-39$, and $\left(\mathrm{A}^{\prime}-\mathrm{C}^{\prime}\right)$, anterograde labeling in a rostrocaudal sequence. Darker areas correspond to areas of higher density of terminals. Stippled areas correspond to fiber tracts. Abbreviations as in Fig. 1 and APTV, anterior pretectal nucleus, ventral part; EP, entopeduncular nucleus; Gu, gustatory nucleus; PoMn, posteromedian nucleus; SNR, substantia nigra, reticular part; SPF, subparafascicular nucleus; VPM, ventral posteromedial nucleus. 
No significant differences were found between the ultrastructural characteristics of nigral and pallidal axon terminals, and both displayed a common pattern of synaptic innervation of their targets (Grofová and Rinvik, 1974; Kultas-Ilinsky et al., 1983; Kultas-Ilinsky and Ilinsky, 1990; Sidibé et al., 1997). These studies have shown that the main postsynaptic target of the afferent fibers are the postsynaptic dendrites of relay cells (Grofová and Rinvik, 1974; Kultas-Ilinsky et al., 1983; Kultas-Ilinsky and Ilinsky, 1990; Sidibé et al., 1997) or identified thalamocortical neurons (Kayahara and Nakano, 1996; Sakai et al., 1998).

The functional segregation of corticostriatal projections is largely maintained through the circuitry of the basal ganglia (Alexander et al., 1986; Parent and Hazrati, 1995a), and it is also preserved to a high extent in the pallidothalamic projection (Sidibé et al., 1997). Thus, the ventrolateral two-thirds of the internal segment of the globus pallidus, which receive projections from the sensorimotor striatum, project to the principal ventrolateral nucleus and the central part of the centromedian nucleus. In turn, the dorsal one-third and the rostromedial pole of the internal segment of the globus pallidus, which receive projections from the associative and limbic striatum, project to the parvocellular ventral anterior nucleus and the rostrodorsal part of the parafascicular nucleus (Sidibé et al., 1997). Therefore some associative and limbic cortical information, which is largely processed in segregated corticostriatopallidal channels, converges to common thalamic nuclei.

Finally, the external segment of the globus pallidus projects to the reticular thalamic nucleus (see Hazrati and Parent, 1991, and Gandia et al., 1993 and references therein). In the rat, the paraventricular, lateral habenular and mediodorsal nuclei are also targets of the globus pallidus (see references in Heimer et al., 1995). Interestingly, the pallidoreticular projections in the rat are also segregated from the nigral afferents to the reticular thalamic nucleus (Gandia et al., 1993). These results illustrate the existence of another important route through which the basal ganglia, via their output nuclei, may control the thalamic flow towards the cerebral cortex or towards brainstem structures like the superior colliculus, and may also control the intrathalamic neural communication (see references in Gandia et al., 1993).

\section{Overlapping thalamic territories between the input and the output projections of the basal ganglia}

Abundant studies have dealt with the relationships between the output of the basal ganglia and the thalamocortical projection at different levels, and some of the more recent ones have compared the pallidal/nigral terminal fields vs. thalamocortical neurons, by means of either single or double-labeling techniques at the light and/or electron microscopic levels, or using transneuronal techniques (Schell and Strick, 1984; Ilinsky et al., 1985; Alexander et al., 1986; Groenewegen, 1988; Alexander et al., 1990; Hoover and Strick, 1993; Kayahara and Nakano, 1996; Sakai et al., 1998). In contrast, little has been reported regarding the relationships between the output of the basal ganglia and the thalamic input to the striatum (de las Heras et al., 1997, 1998a). Double-labeling experiments were carried out in the cat injecting in the same animal either one or two retrograde fluorescent tracers in the caudate nucleus, and HRP-WGA as an anterograde tracer, in the substantia nigra (Fig. 4, for methodological considerations see de las Heras et al., 1998a). The thalamic distribution of retrogradely labeled thalamostriatal neurons and anterogradely labeled nigrothalamic terminals was analyzed in adjacent sections and compared in superimposed drawings. Wide overlapping thalamic territories were observed between the neurons projecting to the caudate nucleus and the nigral afferents in the rostral nuclei of the ventral thalamic group (ventral anterior nucleus, ventral anterior-ventral lateral complex and ventral medial nucleus), whereas more restricted areas of overlap were visible in the rostral (rhomboid, paracentral, central lateral, dorsal mediodorsal nuclei) and caudal intralaminar nuclei (centromedian-parafascicular complex) (Fig. 4B-B' and de las Heras et al., 1998a). In the rat, the overlapping thalamic territories were visualized in the same section, by means of double-labeling experiments using Fluorogold as retrograde tracer and byotinilated dextran amine (BDA) as the anterograde tracer (Fig. 5, for methodological consider-

Fig. 4. Schematic drawings illustrating the overlapping territories between the thalamostriatal neurons projecting to the caudate nucleus, and the nigrothalamic terminal fields in the cat, obtained from adjacent sections and depicted onto one. The thalamostriatal neuronal populations were obtained either after a single retrograde fluorescent tracer injection or after concomitant injections of the two retrograde fluorescent tracers FB and DY. The nigrothalamic terminal fields were obtained by means of injections of the anterograde tracer HRP-WGA. Left, A, localization in a sagittal drawing of the DY deposit in the caudate nucleus (middle) injection site in the substantia nigra, and B, overlapping territories between retrogradely labeled neurons (yellow dots) and nigral terminal fields (light red) from case C-35. Right (A'), localization in a sagittal drawing of the FB and DY injections in different rostrocaudal sectors of the cat caudate nucleus (middle) injection site in the substantia nigra, and (B'), overlapping territories between retrogradely labeled neurons (yellow or blue dots) and nigral terminal fields (light red), from case C-36. Each dot represents one retrogradely labeled neuron. FB neurons are depicted in blue and DY neurons in yellow. Abbreviations as in Fig. 2 and AC, anterior commissure; AV, anteroventral nucleus; $\mathrm{CP}$, cerebral peduncle; Ep, entopeduncular nucleus; Re, reuniens nucleus; Rt, reticular thalamic nucleus. 
C-30R

C-24R
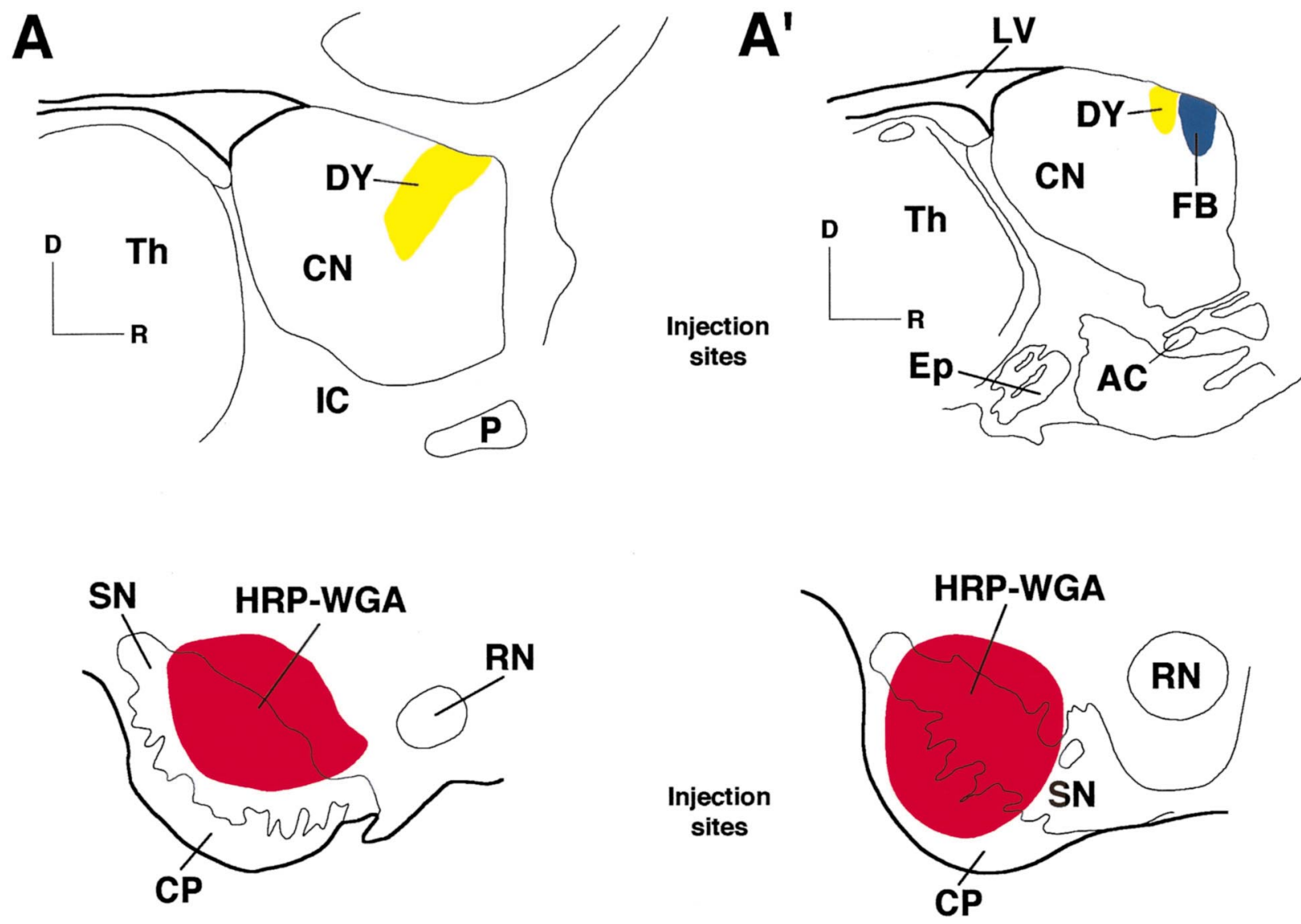

B

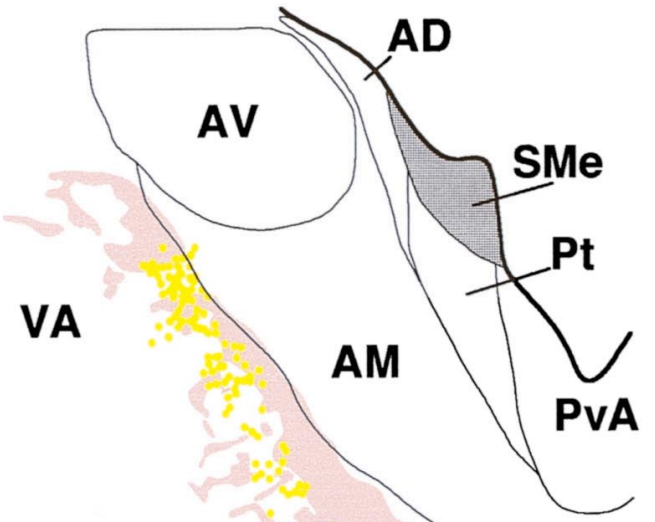

B'

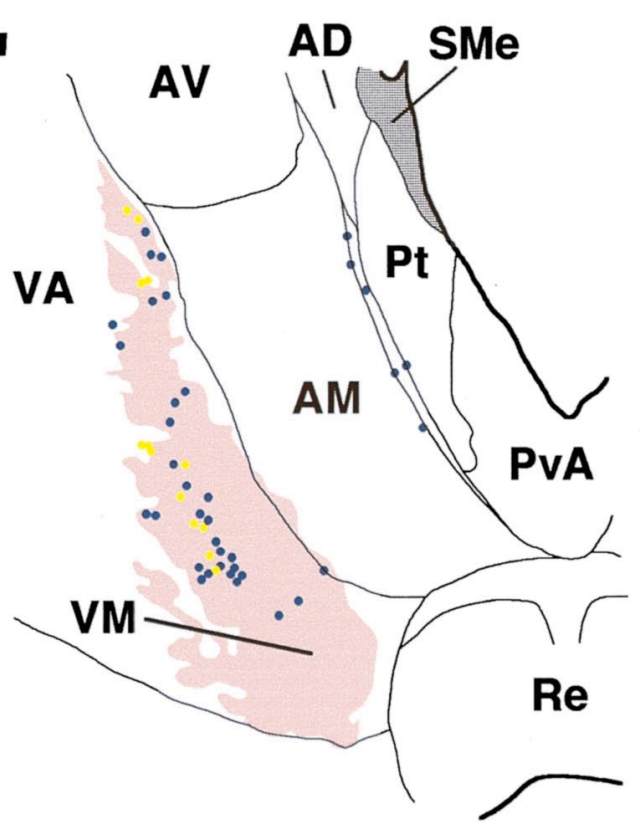

- FB neurons

DY neurons

HRP-WGA terminal fields

Fig. 4. (Continued) 


\section{C-39}
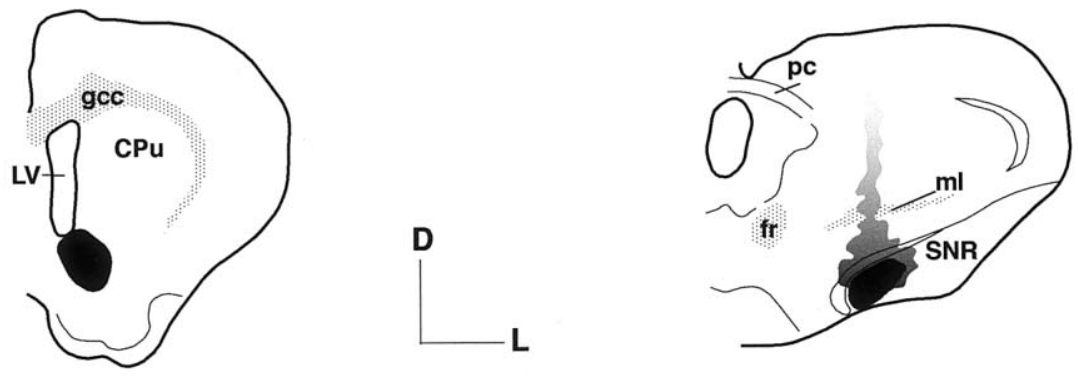

A

B
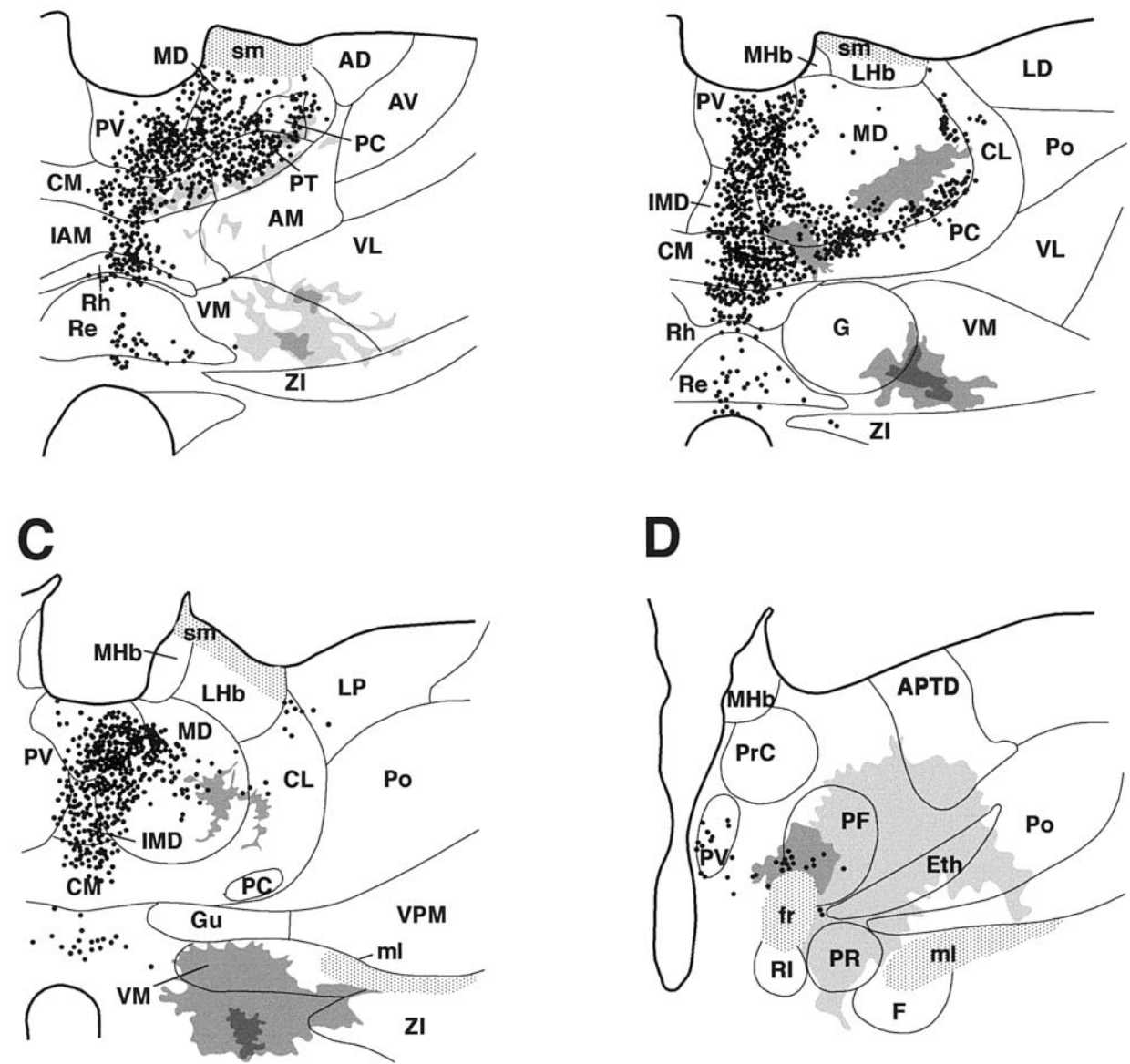

D

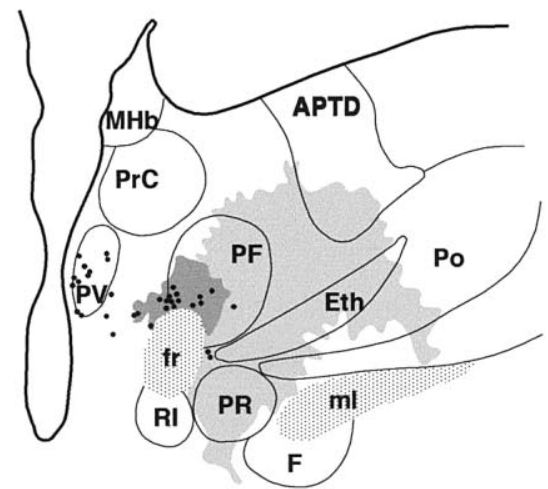

Fig. 5. Schematic drawings illustrating the thalamic areas of overlap between the thalamostriatal neurons projecting to the ventral striatum and the nigrothalamic projections in the rat, after single injections of the retrograde tracer FG in the ventral striatum and single injections of the anterograde tracer BDA. The double-labeling was visualized in the same section as depicted in the drawings. (Top) left, injection site in the ventral striatum, and right, injection site in the substantia nigra. (A-D), rostrocaudal sequence of overlapping territories between retrogradely labeled thalamostriatal neurons and nigrothalamic afferents. Neurons retrogradely labeled with FG are represented by dots. Anterogradely labeled terminal fields are represented by shaded areas. Darker areas correspond to areas with a higher density of terminals. Stippled areas correspond to fiber tracts. Abbreviations as in Figs. 1 and 3.

Fig. 6. Microphotographs of coronal sections through the rat brain from case C-1, illustrating the overlapping territories between the thalamostriatal neurons projecting to ventral portions of the caudate putamen complex, after an injection of the retrograde tracer FG, and the nigrothalamic fiber terminals, after and injection of the anterograde tracer BDA. (A), deposit of FG in the ventral portion of the caudate putamen complex. (B), injection of BDA in the substantia nigra. (C), coronal section through the caudal thalamus showing the retrogradely labeled cells in the medial portion of the parafascicular nucleus, immersed within a terminal field of nigrothalamic fibers. (D), boxed area in (C), at a higher magnification. Scale bar: (A-C), $400 \mu \mathrm{m}$; (D), $50 \mu \mathrm{m}$. Abbreviations as in Fig. 1, and ac, anterior commissure; PVP, posterior paraventricular nucleus; SNC, substantia nigra pars compacta; SNR, substantia nigra pars reticulata; VTA, ventral tegmental area of Tsai. 


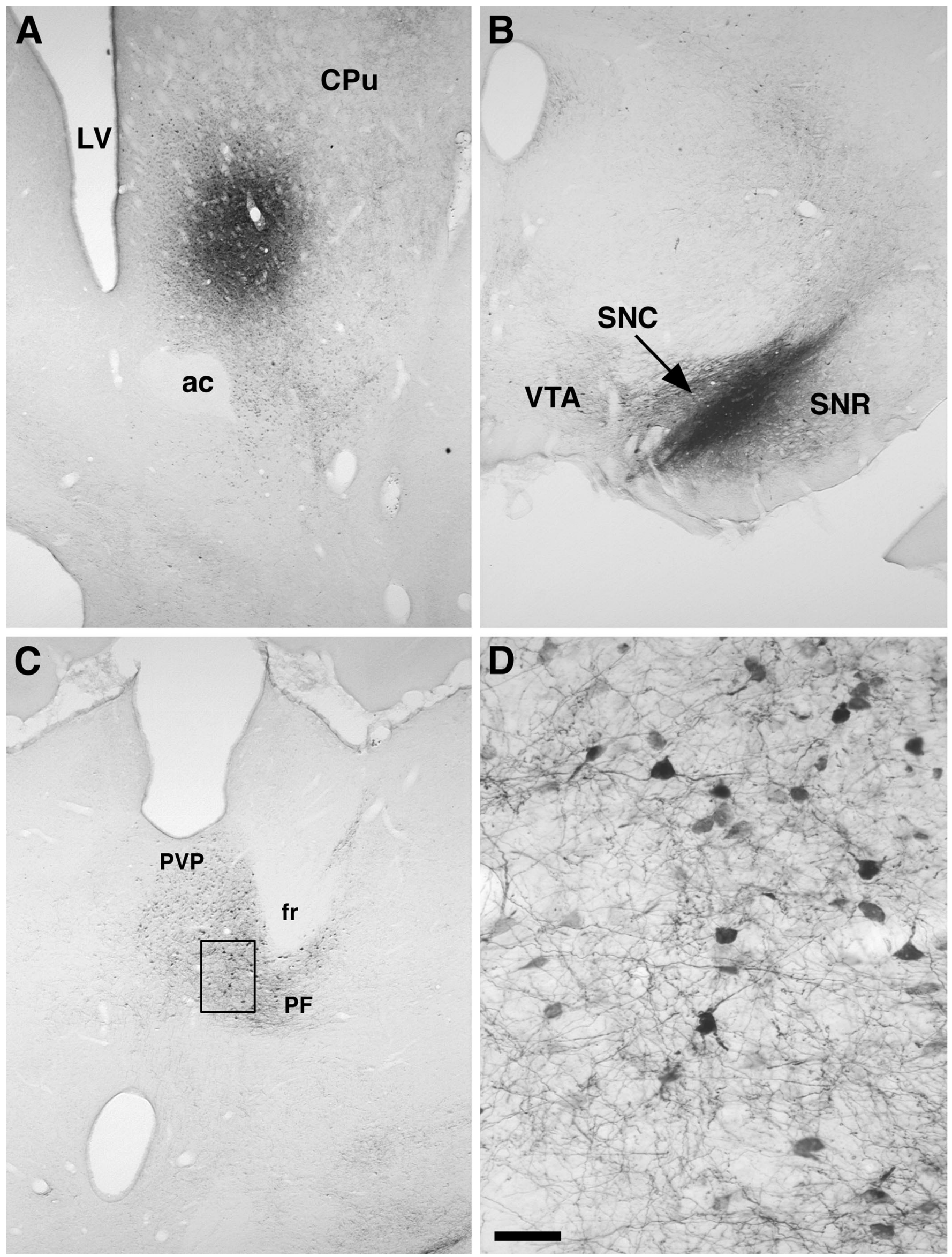


ations see Lanciego et al., 1998). In this case, the retrograde tracer was placed in the nucleus accumbens, and the retrograde labeled neurons were located, as expected (see Section 2), in the midline thalamic nuclei, in the mediodorsal nucleus and dorsomedially in the rostral intralaminar nuclei (Fig. 5A-D). Remarkably, the nigral terminal field, that was patchy in the mediodorsal nucleus and in the rostral intralaminar nuclei, displayed a pattern that seemed to be complementary to the retrogradely labeled neurons, either bordering the bulk of the thalamostriatal neurons (Fig. 5A), or occupying areas of less labeling (Fig. 5C) or even gaps among areas of labeling (Fig. 5B). Despite this complementary pattern, the marginal borders of the nigral terminal fields were still in contact with at least some thalamostriatal neurons. Fig. 6 illustrates another example in the rat of convergence between thalamostriatal neurons projecting to ventral regions of the caudate putamen complex, and the nigrothalamic terminals (Fig. 6, for methodological considerations see Lanciego et al., 1998).

These studies provide evidence for the existence of thalamic areas in which the input and the output of the basal ganglia converge. In fact, these sets of experiments show the possible existence of feedback circuits through the thalamus, in the basal ganglia organization. Several ultrastructural studies of nigrothalamic or pallidothalamic terminals have reported that the main postsynaptic target of these afferent fibers are the dendrites of projection neurons (Grofová and Rinvik, 1974; Kultas-Ilinsky et al., 1983; Kultas-Ilinsky and Ilinsky, 1990) which in some cases have been clearly identified as thalamocortical neurons (Sakai et al., 1998). Ultrastructural studies of double-labeling experiments are being carried out in order to elucidate the relation between afferents from nigral and pallidal afferents and the thalamic projection neurons to the striatum. This would represent the anatomical evidence of the existence and putative functionality of these feedback circuits or striato-pallido/nigro-thalamo-striatal loops.

Although the exact function of these potential circuits is still poorly understood, these findings suggest that the information processed by the basal ganglia and directed to the cerebral cortex through the thalamus, could be reaching again the basal ganglia via the striatum, and thus influencing its overall organization. It could also be another way of intrastriatal communication, by which the processed information could reach functionally different striatal modules.

\section{Functional considerations}

As far as the morphofunctional organization of the basal ganglia is concerned, a major finding discussed in the previous section is the existence, at least in the rat and cat, of areas of convergence within the thalamus of the input and the output systems of the basal ganglia. These anatomical data support the hypothesis that the output of the basal ganglia might participate in feedback subcortical circuits through the thalamostriatal projections. These circuits, however, may be established either directly through the pallidothalamic and nigrothalamic projections, or indirectly through the pallidoreticular projections. In our opinion, it is particularly appealing the idea that the final outcome of the basal ganglia processing can be conveyed either directly to the cerebral cortex via thalamic relay nuclei, or sent back to the basal ganglia themselves at the striatal level through the thalamostriatal pathway. A third and very suggestive possibility is that this information already processed in the basal ganglia can be directed to both the cerebral cortex and the striatum using the thalamic cells which project to the cortex and the striatum by means of collaterals.

These feedback circuits of the basal ganglia through the thalamus might thus represent the continuation at the subcortical level of the parallel circuits, which several authors support as the way of processing within the basal ganglia, and even the final link closing the cortico-striato-thalamo-striatal/cortical loops. However, a certain interaction among these parallel circuits reaching the thalamus might also take place at the thalamic level, by means of either interneurons or most probably via the reticular thalamic nucleus.

With or without interaction at the thalamic level of the output information of the basal ganglia which reaches the thalamus through parallel or convergent ways, these feedback circuits of the basal ganglia through the thalamus may represent another way of intrastriatal communication. In fact, some anatomical data presented in this revision illustrate that the output of the basal ganglia reaches thalamic territories occupied by thalamostriatal neurons that are projecting to different striatal sectors. Thus, we may hypothesize that the output of the basal ganglia concerning a specific part of the striatum might be influencing, via the thalamus, additional striatal areas and possibly, amplifying the overall response of the basal ganglia to the cerebral cortex and/or the brainstem.

Finally, a third functional consideration is that the reticular thalamic nucleus may also play a crucial role in establishing feedback circuits of the basal ganglia through the thalamus. Two possibilities should be taken into account. First, the pallidoreticular and nigroreticular connections could have the global effect of inhibiting or activating different neurons in the reticular thalamic nucleus depending on the corticostriatal excitation. The second possibility is that the reticular thalamic cells might differently influence the thalamocortical and thalamostriatal neurons or even concrete pools of cells within these thalamic groups. 


\section{Acknowledgements}

The authors would like to thank Ainhoa Moreno for her excellent technical assistance. This study was supported by FIS 93/0337, FIS 96/0488, Fundación Marcelino Botín and Universidad de Navarra.

\section{References}

Alexander, G.E., DeLong, M.R., Strick, P.L., 1986. Parallel organization of functionally segregated circuits linking basal ganglia and cortex. Annu. Rev. Neurosci. 9, 357-381.

Alexander, G.E., Crutcher, M.D., 1990. Functional architecture of basal ganglia circuits: neural substrates of parallel processing. Trends Neurosci. 13, 266-271.

Alexander, G.E., Crutcher, M.D., DeLong, M.R., 1990. Basal gangliathalamocortical circuits: parallel substrates for motor, oculomotor, 'prefrontal' and 'limbic' functions. Prog. Brain Res. 85, 119-146.

Alheid, G.F., Heimer, L., Switzer III, R.C., 1990. Basal ganglia. In: Paxinos, G. (Ed.), The Human Nervous System. Academic Press, San Diego, pp. 483-583.

Asanuma, C., Thach, V.T., Jones, E.G., 1983. Distribution of cerebellar terminations and their relation to other afferent terminations in the ventral lateral thalamic region of the monkey. Brain Res. 286, 237-265.

Beckstead, R.M., 1984a. The thalamostriatal projection in the cat. J. Comp. Neurol. 223, 313-346.

Beckstead, R.M., 1984b. A projection to the striatum from the medial subdivision of the posterior group of the thalamus in the cat. Brain Res. 300, 351-356.

Berendse, H.W., Voorn, P., te Kortschot, A., Groenewegen, H.J., 1988. Nuclear origin of thalamic afferents of the ventral striatum determines their relation to patch/matrix configurations in enkephalinimmunoreactivity in the rat. J. Chem. Neuroanat. 1, 3-10.

Berendse, H.W., Groenewegen, H.J., 1990. Organization of the thalamostriatal projections in the rat, with special emphasis on the ventral striatum. J. Comp. Neurol. 299, 187-228.

Chesselet, M.-F., Delfs, J.M., 1996. Basal ganglia and movement disorders: an update. Trends Neurosci. 19, 417-422.

Chesselet, M.-F., Delfs, J.M., 1997. Reply. Trends Neurosci. 20, 153.

Cowan, W.M., Powell, T.P.S., 1955. The projection of the midline and intralaminar nuclei of the thalamus of the rabbit. J. Neurol. Neurosurg. Psychiatr. 18, 266-279.

de las Heras, S., Gandia, J.A., Giménez-Amaya, J.M., 1994. The reticular thalamic nucleus and the output nuclei of the basal ganglia: a neuroanatomical view based on hodological studies. In: Percheron, G., McKenzie, J.S., Féger, J. (Eds.), The Basal Ganglia IV: New Ideas and Data on Structure and Function. Plenum Press, New York, pp. 127-134.

de las Heras, S., Mengual, E., Velayos, J.L., Giménez-Amaya, J.M., 1997. New data on the anatomical organization of the thalamostriatal projections. Adv. Neurol. 74, 69-81.

de las Heras, S., Mengual, E., Giménez-Amaya, J.M., 1998a. Overlapping territories between the thalamostriatal and nigrothalamic projections in cats. NeuroReport 9, 275-278.

de las Heras, S., Mengual, E., Velayos, J.L., Giménez-Amaya, J.M., 1998b. Re-examination of topographic distribution of thalamic neurons projecting to the caudate nucleus. A retrograde labeling study in the cat. Neurosci. Res. 31, 283-293.

de las Heras, S., Mengual, E., Giménez-Amaya, J.M., 1999. Double retrograde tracer study of the thalamostriatal projections to the cat caudate nucleus. Synapse 32, 80-92.

Hoover, J.E., Strick, P.L., 1993. Multiple output channels in the basal ganglia. Science 259, 819-821.
Deschênes, M., Bourassa, J., Parent, A., 1995. Two different types of thalamic fibers innervate the rat striatum. Brain Res. 701, 288-292.

Deschênes, M., Bourassa, J., Doan, V.D., Parent, A., 1996. A single-cell study of the axonal projections arising from the posterior intralaminar thalamic nuclei in the rat. Eur. J. Neurosci. 8, 329-343.

De Vito, J.L., Anderson, M.E., 1982. An autoradiographic study of efferent connections of the globus pallidus in Macaca mulatta. Exp. Brain Res. 46, 107-117.

Drooglever-Fortuyn, J., Stefens, R., 1951. On the anatomical relations of the intralaminar and midline cells of the thalamus. Electroenceph. Clin. Neurophysiol. 3, 393-400.

Erro, E., Lanciego, J.L., de las Heras, S., Giménez-Amaya, J.M., 1998. A comprehensive retrograde tracer study of the thalamostriatal projections in the rat. Soc. Neurosci. Abstr. 24, 662.

Féger, J., 1997. Updating the functional model of the basal ganglia. Trends Neurosci. 20, 152-153.

Fénelon, G., François, C., Percheron, G., Yelnik, J., 1991. Topographic of the neurons of the central complex (centre-median-parafascicular complex) and of other thalamic neurons projecting to the striatum in macaques. Neuroscience 45, 495-510.

Gandia, J.A., de las Heras, S., García, M., Giménez-Amaya, J.M., 1993. Afferent projections to the reticular thalamic nucleus from the globus pallidus and the substantia nigra in the rat. Brain Res. Bull. 32, 351-358.

Gerfen, C.R., Wilson, C.J., 1996. The basal ganglia. In: Swanson, L.W., Björklund, A., Hökfelt, T. Jr. (Eds.), Handbook of Chemical Neuroanatomy, Integrated Systems of the CNS, Part III, vol. 12. Elsevier, New York, pp. 371-468.

Giménez-Amaya, J.M., 1991a. The association cortex and the basal ganglia: a neuroanatomical view upon their relationship based on hodological studies. J. Hirnforsch. 32, 501-510.

Giménez-Amaya, J.M., 1991b. Una visión neuroanatómica de los ganglios basales con algunas implicaciones en su fisiopatología. Rev. Med. Univ. Navarra 36, 131-136.

Giménez-Amaya, J.M., McFarland, N.R., de las Heras, S., Haber, S.N., 1995. Organization of thalamic projections to the ventral striatum in the primate. J. Comp. Neurol. 354, 127-149.

Graybiel, A.M., 1995. The basal ganglia. Trends Neurosci. 18, 60-62.

Graybiel, A.M., Ragsdale, C.R. Jr., 1979. Fiber connections of the basal ganglia. Prog. Brain Res. 51, 239-283.

Groenewegen, H.J., 1988. Organization of the afferent connections of the mediodorsal thalamic nucleus in the rat, related to the mediodorsal-prefrontal topography. Neuroscience 24, 379-431.

Grofová, Y., Rinvik, E., 1974. Cortical and pallidal projections to the nucleus ventralis lateralis thalami. Electron microscopical studies in the cat. Anat. Embryol. (Berl.) 146, 113-132.

Hazrati, L.-N., Parent, A., 1991. Projection from the external pallidum to the reticular thalamic nucleus in the squirrel monkey. Brain Res. 550, 142-146.

Heimer, L., Zahm, D.S., Alheid, G.F., 1995. Basal ganglia. In: Paxinos, G. (Ed.), The Rat Nervous System. Academic Press, San Diego, pp. 579-628.

Hendry, S.H.C., Jones, E.G., Graham, J., 1979. Thalamic relay nuclei for cerebellar and certain related fiber systems in the cat. J. Comp. Neurol. 185, 679-714.

Ilinsky, I.A., Jouandet, M.L., Goldman-Rakic, P.S., 1985. Organization of the nigrothalamocortical system in the Rhesus monkey. J. Comp. Neurol. 236, 315-330.

Ilinsky, I.A., Kultas-Ilinsky, K., 1987. Sagittal cytoarchitectonic maps of the Macaca mulatta thalamus with a revised nomenclature of the motor-related nuclei validated by observations on their connectivity. J. Comp. Neurol. 262, 331-364.

Jayaraman, A., 1985. Organization of thalamic projections in the nucleus accumbens and in the caudate nucleus in cats and its relation with hippocampal and other subcortical afferents. J. Comp. Neurol. 231, 396-420. 
Jones, E.G., Leavitt, R.Y., 1974. Retrograde axonal transport and the demonstration of non-specific projections to the cerebral cortex and striatum from thalamic intralaminar nuclei in the rat, cat and monkey. J. Comp. Neurol. 154, 349-378.

Kayahara, T., Nakano, N., 1996. Pallido-thalamo-cortical connections: an electron microscopic study in the macaque monkey. Brain Res. 706, 337-342.

Kultas-Ilinsky, K., Ilinsky, I., Warton, S., Smith, K.R., 1983. Fine structure of nigral and pallidal afferents in the thalamus: an EM autoradiography study in the cat. J. Comp. Neurol. 216, 390-405.

Kultas-Ilinsky, K., Ilinsky, I.A., 1986. Neuronal and synaptic organization of the motor nuclei of the mammalian thalamus. In: Current Topics in Research on Synapses, vol. 3. Alan R. Liss, New York, pp. $77-145$.

Kultas-Ilinsky, K., Ilinsky, I.A., 1990. Fine structure of the magnocellular subdivision of the ventral anterior thalamic nucleus (VAmc) of Macaca mulatta: II. Organization of nigrothalamic afferents as revealed with EM autoradiography. J. Comp. Neurol. 294, 479489.

Lanciego, J.L., Wouterlood, F.G., Erro, E., Giménez-Amaya, J.M., 1998. Multiple axonal tracing: simultaneous detection of three tracers in the same section. Histochem. Cell. Biol. 110, 509-515.

Macchi, G., Bentivoglio, M., Molinari, M., Minciacchi, D., 1984. The thalamo-caudate versus thalamo-cortical projections as studied in the cat with fluorescent retrograde double labeling. Exp. Brain Res. 54, 225-239.

Marsden, C.D., Obeso, J.A., 1994. The functions of the basal ganglia and the paradox of stereotaxic surgery in Parkinson's disease. Brain $117,877-897$.

Nakano, K., Hasegawa, Y., Tokushige, A., Nakagawa, S., Kayahara, T., Mizuno, N., 1990. Topographical projections from the thalamus, subthalamic in the Japanese monkey, Macaca fuscata. Brain Res. 537, 54-68.

Nauta, H.J.W., 1979. Projections of the pallidal complex: an autoradiographic study in the cat. Neuroscience 4, 1853-1873.

Nauta, H.J.W., Pritz, M.B., Lasek, R.J., 1974. Afferents to the rat caudoputamen studied with horseradish peroxidase: an evaluation of a retrograde neuroanatomical research method. Brain Res. 67, 219-238.

Nauta, W.J.H., Feirtag, M., 1986. Fundamental Neuroanatomy. W.H. Freeman and Co, New York.

Parent, A., 1986. Comparative Neurobiology of the Basal Ganglia. John Wiley \& Sons, New York.

Parent, A., Mackey, A., De Bellefeuille, L., 1983. The subcortical afferents to caudate nucleus and putamen in primate: a fluorescence retrograde double labeling study. Neuroscience 10, 1137-1150.

Parent, A., Hazrati, L.-N., 1995a. Functional anatomy of the basal ganglia. I. The cortico-basal ganglia-thalamo-cortical loop. Brain Res. Rev. 20, 91-127.

Parent, A., Hazrati, L.-N., 1995b. Functional anatomy of the basal ganglia. II. The place of subthalamic nucleus and external pallidum in basal ganglia circuitry. Brain Res. Rev. 20, 128-154.

Percheron, G., François, C., Yelnik, J., Talbi, B., Meder, J.F., Fénelon, G., 1993. The pallidal and nigral thalamic territories and the problem of the anterior part of the lateral region in primates. In: Minciacchi, D., Molinari, M., Macchi, G., Jones, E.G. (Eds.), Thalamic Networks for Relay and Modulation. Pergamon Press, Oxford, pp. 145-154.

Percheron, G., François, C., Talbi, B., Yelnik, J., Fénelon, G., 1996. The primate motor thalamus. Brain Res. Rev. 22, 93-181.

Philipson, O.T., Griffiths, A.C., 1985. The topographic order of inputs to nucleus accumbens in the rat. Neuroscience 16, 275-296.

Powell, T.P.S., Cowan, W.M., 1954. The connexions of the midline and intralaminar nuclei of the thalamus of the rat. J. Anat. 88, 307-319.

Powell, T.P.S., Cowan, W.M., 1956. A study of thalamo-striate relations in the monkey. Brain 79, 364-390.

Ragsdale, C.W.J.r., Graybiel, A.M., 1991. Compartmental organiza- tion of the thalamostriatal connection in the cat. J. Comp. Neurol. 311, 134-167.

Royce, G.J., 1978. Autoradiographic evidence for a discontinuous projection to the caudate nucleus from the centromedian nucleus in the cat. Brain Res. 146, 145-150.

Sadikot, A.F., Parent, A., François, C., 1992a. Efferent connections of the centromedian and parafascicular thalamic nuclei in the squirrel monkey: a PHA-L study of subcortical projections. J. Comp. Neurol. 315, 137-159.

Sadikot, A.F., Parent, A., Smith, Y., Bolam, J.P., 1992b. Efferent connections of the centromedian and parafascicular thalamic nuclei in the squirrel monkey: a light and electron microscopic study of the thalamostriatal projection in relation to striatal heterogeneity. J. Comp. Neurol. 320, 228-242.

Sakai, S., Smith, A., 1992. Distribution of nigrothalamic projections in the dog. J. Comp. Neurol. 318, 83-92.

Sakai, S.T., Patton, K., 1993. Distribution of cerebellothalamic and nigrothalamic projectios in the dog: a double anterograde tracing study. J. Comp. Neurol. 330, 183-194.

Sakai, S.T., Inase, M., Tanji, J., 1996. Comparison of cerebellothalamic and pallidothalamic projections in the monkey (Macaca fuscata): a double anterograde labeling study. J. Comp. Neurol. 368, $215-228$.

Sakai, S.T., Grofova, I., Bruce, K., 1998. Nigrothalamic projections and nigrothalamocortical pathway to the medial agranular cortex in the rat: single- and double-labeling light and electron microscopic studies. J. Comp. Neurol. 391, 506-525.

Sato, M., Itoh, K., Mizuno, N., 1979. Distribution of thalamo-caudate neurons in the cat as demonstrated by horseradish peroxidase. Exp. Brain Res. 34, 143-153.

Schell, G.R., Strick, P.L., 1984. The origin of thalamic inputs to the arcuate premotor and supplementary motor areas. J. Neurosci. 4, $539-560$.

Schneider, J.S., Rothblat, D.S., 1996. Alterations in intralaminar and motor thalamic physiology following nigrostriatal dopamine depletion. Brain Res. 742, 25-33.

Schultz, W., 1997. Dopamine neurons and their role in reward mechanisms. Curr. Opin. Neurobiol. 7, 191-197.

Sidibé, M., Bevan, M.D., Bolam, J.P., Smith, Y., 1997. Efferent connections of the internal globus pallidus in the squirrel monkey: I. Topography and synaptic organization of the pallidothalamic projection. J. Comp. Neurol. 382, 323-347.

Smith, Y., Parent, A., 1986. Differential connections of caudate nucleus and putamen in the squirrel monkey (Saimiri sciureus). Neuroscience 18, 347-371.

Smith, Y., Shink, E., Sidibé, M., 1998. Neuronal circuitry and synaptic connectivity of the basal ganglia. Neurosurg. Clin. North Am. 9, 203-222.

Stepniewska, I., Preuss, T.M., Kaas, J.H., 1994. Thalamic connections of the primary motor cortex (M1) of owl monkeys. J. Comp. Neurol. 349, 558-582.

Steriade, M., Jones, E.G., McCormick, D.A., 1997. Thalamus. Elsevier, Oxford.

Tanaka, D. Jr., Isaacson, L.G., Trosko, B.K., 1986. Thalamostriatal projections from the ventral anterior nucleus in the dog. J. Comp. Neurol. 247, 56-68.

van der Kooy, D., 1979. The organization of the thalamic, nigral and raphe cells projecting to the medial vs. lateral caudate-putamen in rat: a fluorescent retrograde double labeling study. Brain Res. 169, 381-387.

Veening, J.G., Cornelissen, F.M., Lieven, P.A.J.M., 1980. The topical organization of the afferents to the caudatoputamen of the rat. A horseradish peroxidase study. Neuroscience 5, 1253-1268.

Vogt, C., Vogt, O., 1941. Thalamusstudien I-III. I. Zur Einfürung. II Homogenität und Grenzgestaldung der Grisea des Thalamus. III. Das Griseum centrale (centrum medianum Luys). J. Psychol. Neurol. (Leipzig) 50, 31-154.

Wichmann, T., DeLong, M.R., 1996. Functional and pathophysiological models of the basal ganglia. Curr. Opin. Neurobiol. 6, 751-758. 